Stability and Success of Regional Fisheries Management Organizations

Pedro Pintassilgo

Michael Finus

Marko Lindroos

Gordon Munro

Stirling Economics Discussion Paper 2008-11

June 2008

Online at http://www.economics.stir.ac.uk 


\title{
STABILITY AND SUCCESS OF REGIONAL FISHERIES MANAGEMENT ORGANIZATIONS
}

\author{
PEDRO PINTASSILGO \\ Faculty of Economics \\ University of Algarve \\ Faro, Portugal \\ MICHAEL FINUS* \\ Department of Economics \\ University of Stirling \\ Stirling, Scotland \\ MARKO LINDROOS \\ Department of Economics and Management \\ University of Helsinki \\ Helsinki, Finland \\ GORDON MUNRO \\ Department of Economics \\ University of British Columbia \\ Vancouver, Canada; \\ Centre for the Economics and Management of Aquatic Resources \\ University of Portsmouth \\ Portsmouth, England
}

SHORT TITLE: STABILITY OF REGIONAL FISHERIES ORGANIZATIONS

* Corresponding author. Address: Department of Economics, University of Stirling, Stirling, FK9 4LA, UK. Email: michael.finus@stir.ac.uk; Tel: +44(0)1786467481; Fax: +44(0)1786467469. 


\title{
STABILITY AND SUCCESS OF REGIONAL FISHERIES MANAGEMENT ORGANIZATIONS
}

\begin{abstract}
According to international law, straddling fish stocks should be managed cooperatively through Regional Fisheries Management Organizations (RFMOs). This paper analyzes the stability and success of these organizations through a game in partition function form based on the classical Gordon-Schaefer bioeconomic model. It is shown that the larger the number of fishing states that compete for the fish stock the higher are the relative gains from full cooperation, but the lower is the likelihood of large RFMOs being stable. Moreover, the success of coalition formation is positively correlated with the degree of production cost asymmetry among fishing states and negatively with the overall level of efficiency.
\end{abstract}

JEL References: C72; Q22.

Keywords: straddling fish stock, regional fisheries management organizations, unregulated fishing, bioeconomic model, coalition formation model, free-riding. 


\section{Introduction}

The 1982 UN Convention on the Law of the Sea (UN, 1982) brought forth the regime of 200 nautical miles coastal state Exclusive Economic Zones (EEZs), which revolutionized the management of world capture fisheries. However, an important aspect was not effectively addressed by the 1982 UN Convention, namely the management of fisheries resources to be found both within the coastal state EEZ and the adjacent high seas, where the resources are subject to exploitation by so called distant water fishing states. These fishery resources are commonly referred to as straddling fish stocks ${ }^{2}$.

Such fish stocks, which account for about 20 per cent of the worlds capture fishery harvests (Munro et al. 2004), were subject to heavy overexploitation in the decade following the advent of the 1982 UN Convention. This led to further action by the UN in the first half of the 1990s, resulting in a supplement to the 1982 UN Convention in the form of an international agreement, popularly known as the 1995 UN Fish Stocks Agreement (UN, 1995). Under this agreement, straddling fish stocks are to be managed, on a region by region basis, by Regional Fisheries Management Organizations (RFMOs), having as members all coastal states and distant water fishing states claiming to have a "real interest" in the relevant fish stocks (UN, 1995, Article 8). Examples of such RFMOs are provided by the Northwest Atlantic Fisheries Organization (NAFO), and the Northeast Atlantic Fisheries Commission (NEAFC).

Under the terms of the 1995 UN Fish Stocks Agreement, only those states, which are members of a given RFMO, or which agree to abide by its conservation and management measures, are to have access to the fishery resources under the governance of the RFMO (UN, 1995, Article 8(4)). However, the cooperative efforts of RFMOs have frequently been undermined by the fishing activities of non-members, in their exclusive economic zones or in the

2 This broad definition includes what, in the terminology of the Food and Agriculture Organization of the United Nations (FAO), is called highly migratory fish stocks (mainly the six major tuna species). According to Munro et al. (2004) there is no meaningful difference between straddling fish stocks and highly migratory fish stocks as far as economic analysis is concerned. 
high seas, in contravention of the RFMOs' management regimes. These practices are usually labeled as unregulated fishing. While there is general consensus that unregulated fishing is morally reprehensible, it has not, in the past, been entirely clear what members of a RFMO can do to suppress it.

Since membership in RFMOs is voluntary, straddling fish stocks can be regarded as common pool resources shared between RFMOs' members and non-members. Thus, the level of participation and the stability of these organizations in effectively mitigating overfishing are key issues on the management of straddling fish stocks. These issues have mainly been addressed using game theory. For instance, Kaitala and Munro (1997), based on the classical dynamic fisheries bioeconomic model (Clark and Munro, 1975), study the threat to cooperative agreements posed by prospective new members by comparing the charter members' payoffs under a cooperative solution and under complete non-cooperation. Hannesson (1997) and Tarui et al. (2008) analyze the prospects of achieving full cooperation through threat of punishments using dynamic games. Empirical studies on the prospects of cooperative agreements have also been undertaken, e.g. by Kennedy (2003) and Lindroos (2004).

Recently, the partition function approach has been applied to study coalition formation in fisheries (e.g. Pintassilgo, 2003, and Pham Do and Folmer, 2006). The advantage of this approach is that it captures externalities across players compactly and allows one to analyze also the formation and stability of subcoalitions. This approach has been further applied in Pintassilgo and Lindroos (forthcoming) characterizing coalition formation in fisheries based on classical Gordon-Schaefer bioeconomic model, though they assume symmetric players. This assumption has also been adopted by Kwon (2006) who obtained similar results using a dynamic bioeconomic model. 
In this paper, we extend the analysis of Pintassilgo and Lindroos (forthcoming), by relaxing the assumption of symmetric players. ${ }^{3}$ Our main contribution is twofold. Firstly, we provide a comprehensive analysis of the economic and biological fundamentals that influence the success of coalition formation in straddling stock fisheries, e.g. the price of fish, the level and asymmetry of production costs, the number of players, the intrinsic growth rate of the stock and the carrying capacity of the ecosystem. Secondly, we generalize and qualify results obtained for symmetric players. By adopting a probabilistic approach over the parameter range, our analysis is more general than previous studies, which either assumed only two types of players (Hannesson, 1997, and Lindroos, forthcoming), or considered a particular parameter set in a deterministic empirical setting (Kennedy, 2003, and Pintassilgo, 2003).

The paper proceeds as follows. The model, comprising the bioeconomic and the coalition formation model, is presented in section 2. Then, the two-stage fishery coalition game is analyzed backward. In section 3, assuming some coalition formation has taken place in the first stage, we analyze how economic and biological fundamentals effect the fish stock levels and the payoffs of fishing states and hence their incentive to participate in RFMOs. In section 4, we analyze the stability of coalitions in the first stage and determine the overall success of coalition formation. Finally, section 5 summarizes our main results, discusses its policy implications and points to future research issues.

\section{The Model}

\subsection{The Bioeconomic Model}

The bioeconomic model is based on the classical Gordon-Schaefer model (Gordon, 1954). Due to its simplicity, this model has been frequently used for game-theoretic analyses of internationally shared fish resources (e.g. Ruseski, 1998, and Lindroos, forthcoming). It

3 The assumption of symmetric players is widespread in the literature on coalition formation based on the partition function approach, not only on international environmental treaties but also in the context of various economic problems (see e.g. Bloch 2003, and Yi 2003 for an overview). 
captures the relation between the fish stock, $X$, the harvest of an individual player $i, H_{i}$, with the set of players $N=\{1, \ldots, n\}$ representing $n$ different fishing states, and the fishing effort exerted by player $i, E_{i}$, by the following three equations:

$$
\begin{aligned}
& \frac{d X}{d t}=G(X)-\sum_{i=1}^{n} H_{i} \\
& G(X)=r X\left(1-\frac{X}{k}\right) \\
& H_{i}=q E_{i} X
\end{aligned}
$$

where $r$ denotes the intrinsic growth rate of fish, $k$ the carrying capacity of the ecosystem (and thus the equilibrium level of $X$ in the absence of harvesting), and $q$ the catchability coefficient, which constitute the parameters of the model, and $t$ denotes time.

According to (1), the variation of the stock in time is the difference between the stock growth and total harvest. Stock growth is described by the logistic function (2). This inverted Ushaped function implies that stock growth increases up to a maximum value, often referred to as the maximum sustainable yield, which occurs at the stock level $k / 2$. Beyond this level, growth decreases until the stock reaches the carrying capacity of the ecosystem $k$. This captures the phenomenon that for low levels of fish stock growth is high, but once the fish population starts to compete for food, growth decreases until a level is reached at which the population stabilizes at the carrying capacity of the ecosystem. The harvest function (3) indicates that the harvest of each player increases with the catchability coefficient and the stock level (both facilitating harvesting) as well as the fishing effort. The fishing effort can be seen as a physical measure of the inputs devoted to harvesting, such as days spend at sea. 
The steady stock level is given by $d X / d t=0$ in (1). Upon substitution of (2) and (3), the steady state or equilibrium stock level can be expressed as function of the total fishing effort that is constant through time:

$$
X^{*}=\frac{k}{r}\left(r-q \sum_{i=1}^{n} E_{i}\right) \text {. }
$$

This indicates the negative relation between the equilibrium stock and players' total fishing effort, $\sum_{i=1}^{n} E_{i}$. It also illustrates the common pool problem of fisheries: the stock decreases with the individual fishing effort of each fishing state, $E_{i}$. This externality problem is also evident by considering the economic rent or payoff of fishing state $i, \Pi_{i}$, which is defined as:

$$
\Pi_{i}=p H_{i}-c_{i} E_{i}
$$

where $p$ is the price for fish and $c_{i}$ the individual cost per unit of effort of player $i$.

By allowing for different costs per unit of fishing effort, we relax the assumption of symmetric players. The subsequent analysis will stress that this extension leads to fundamental different results.

Substituting (3) into (5), $\Pi_{i}=p q E_{i} X^{*}-c_{i} E_{i}$, illustrates the fact that the revenue of player $i$, $R_{i}=p q E_{i} X^{*}$, is a function of the stock, which, as already pointed out, is a negative function of the fishing effort of all states according to (4) and hence $\partial \Pi_{i} / \partial \sum_{j \neq i} E_{j}<0$. Total cost of player $i$ is given by $T C_{i}=c_{i} E_{i}{ }^{4}$

4 It should be noted that total cost can also be expressed in terms of $H_{i}$ instead of $E_{i}$, $T C_{i}={ }^{C_{i}} H_{i} / q X^{*}$, in which case it is a strictly convex function of harvest $H_{i}$. Then the externality problem shows up in the cost function where the cost of player $i$ is an increasing function of the harvest of the other players as this reduces the stock $X^{*}$ and hence $\partial \Pi_{i} / \partial \sum_{j \neq i} H_{j}<0$ where
$\Pi_{i}=p H_{i}-{ }^{c_{i} H_{i}} / q X^{*}$. 


\subsection{The Coalition Formation Model}

We assume that a RFMO is established with the purpose of managing and conserving a given straddling fish stock. Participation in a RFMO is open to all nations as reflected by Article 8(3) of the UN Fish Stocks Agreement. Moreover, states which decide against membership in a RFMO, cannot be prevented from harvesting.

In order to capture these features, we chose from the set of coalition formation games the single coalition open membership game due to d'Aspremont et al. (1983), which has been frequently applied in the literature to analyze international environmental agreements (e.g. Carraro 2000 and Finus 2003 for an overview). In the first stage, players decide on their participation. Those players that join the RFMO form the coalition and are called members, those that do not join are called non-members and act as singletons. Note that the decisions in the first stage lead to a coalition structure $K=\left\{S, 1_{(n-m)}\right\}$ where $S$ is the non-empty set of $m$ coalition members, $m \in\{1, \ldots, n\}$, and $1_{(n-m)}$ is the vector of $n-m$ singletons. Given the simple structure of the first stage, a coalition structure is fully characterized by coalition $S$. In the second stage, players chose their economic strategies which are fishing efforts in our bioeconomic model. In each stage, strategies (participation and fishing effort) form a Nash equilibrium. The game is solved backward for the subgame-perfect equilibrium.

In the following, we analyze the fishing game according to the sequence of backward induction. We start by analyzing the second stage, assuming that a coalition has been formed. Subsequently, we move to the first stage and analyze the stability of the RFMO.

\section{The Second Stage of Coalition Formation}

\subsection{Preliminaries}

In the second stage, given a coalition structure $K=\left\{S, 1_{(n-m)}\right\}$ formed in the first stage, the vector of equilibrium fishing efforts, $E^{*}$, must satisfy the following inequality system: 


$$
\begin{array}{ll}
\sum_{i \in S} \Pi_{i}\left(E^{S^{*}}(S), E^{-S^{*}}(S)\right) \geq \sum_{i \in S} \Pi_{i}\left(E^{S}(S), E^{-S^{*}}(S)\right) & \forall E^{S}, i \in S \text { and } \\
\Pi_{j}\left(E^{S^{*}}(S), E_{j}^{*}(S), E^{-j^{*}}(S)\right) \geq \Pi_{j}\left(E^{S^{*}}(S), E_{j}(S), E^{-j^{*}}(S)\right) & \forall E_{j}, j \notin S
\end{array}
$$

where $E^{S}$ is the fishing effort vector of coalition $S, E^{-S}$ the effort vector of all states not belonging to $S, E_{j}$ the fishing effort of non-member $j \notin S$, and $E^{-j}$ the fishing vector of all other non-members of $S^{5}$ Asterisks denote equilibrium strategies. From (6) it is evident that equilibrium fishing efforts depend on coalition $S$ (and on the parameters of the model which have been omitted for convenience). Since for every coalition $S$ there is a unique fishing vector $E^{*}(S)$ as we show below, we can simplify notation by denoting the payoff or worth of coalition $S$ by $\Pi_{S}(S)=\sum_{i \in S} \Pi_{i}(S)$ and the payoff or worth of a non-member by $\Pi_{j \notin S}(S)$. Thus, we define a partition function $\Pi$ such that it assigns a single real number $\Pi_{S}(S)$ to coalition $S$ and real numbers $\Pi_{j}(S)$ to every singleton $j \notin S: \Pi: S \mapsto \Pi(S)=$ $\left(\Pi_{S}(S), \Pi_{j}(S)\right)$.

Note that (6) implies that $E^{*}(S)$ is derived as a Nash equilibrium between coalition $S$ (which de facto acts as a meta player; Haeringer 2004) and the $n-m$ singletons to which we refer as coalitional Nash equilibrium. This is to distinguish it from the Nash equilibrium which is identical to the coalitional Nash equilibrium fishing vector if coalition $S$ comprises only a single player, $S=\{i\}$. If coalition $S$ comprises all players, $S=N$, the coalitional Nash equilibrium fishing vector corresponds to the global optimum. In the following, however, we will refer to coalitional Nash equilibrium fishing efforts, stock and payoffs simply as equilibrium fishing efforts, stock and payoffs, respectively, when no misunderstanding is possible.

5 We use superscripts for vectors and subscripts for individual strategies. 
In order to determine the coalitional Nash equilibrium for payoff function (5), we solve the following maximization problems:

$$
\begin{aligned}
& \operatorname{Max}_{E^{S}} \Pi_{S}(S)=\sum_{i \in S} \Pi_{i}(S)=\sum_{i \in S}\left(p H_{i}-c_{i} E_{i}\right) \quad \forall i \in S \\
& \operatorname{Max}_{E_{j}} \Pi_{j \notin S}(S)=p H_{j}-c_{j} E_{j} \quad \forall j \notin S .
\end{aligned}
$$

Since the marginal revenue of the fishing effort is equal for all members, only the coalition member with the lowest unit cost, which we denote by $c_{S}^{\min }$, will harvest. ${ }^{6}$ Consequently, denoting the fishing effort of that player by $E_{S}$ and using (3) and (4), we derive:

$$
\begin{aligned}
& E_{S}=\left\{\begin{array}{l}
\frac{r}{2 q}\left(1-b_{S}^{\text {min }}\right)-\frac{1}{2} \sum_{j \notin S} E_{j} \quad \text { if } \quad \sum_{j \notin S} E_{j}<\frac{r}{q}\left(1-b_{S}^{\text {min }}\right) \\
0 \quad \text { if } \quad \sum_{j \notin S} E_{j} \geq \frac{r}{q}\left(1-b_{S}^{\text {min }}\right)
\end{array}\right. \\
& E_{j}=\left\{\begin{array}{l}
\frac{r}{2 q}\left(1-b_{j}\right)-\frac{1}{2}\left(E_{s}+\sum_{k \neq j \notin S} E_{k}\right) \text { if } E_{s}+\sum_{k \neq j \notin S} E_{k}<\frac{r}{q}\left(1-b_{j}\right) \\
0 \quad \text { if } \quad E_{s}+\sum_{k \neq j \notin S} E_{k} \geq \frac{r}{q}\left(1-b_{j}\right)
\end{array}\right.
\end{aligned}
$$

where $b_{S}^{\text {min }}=\frac{c_{S}^{\min }}{p q k}$ and $b_{j}=\frac{c_{j}}{p q k}$. These parameters are usually referred to as "inverse efficiency parameters" (Mesterton-Gibbons, 1993) because they increase with the cost per unit of effort $c_{i}$ and decrease with the price $p$ and the catchability coefficient $q$. They always lie in the range $[0 ; 1] .^{7}$

6 In order for all coalition members to harvest, one would have to depart from the assumptions of the Gordon-Schaefer model. Possible modifications include a harvest-effort elasticity below one in equation (3) or the assumption of limited fishing capacities.

7 This can easily be shown by noting that the equilibrium stock levels in the open access regime are given by $X_{S}^{O A}=c_{S}^{\min } / p q$ and $X_{j}^{O A}=c_{j} / p q$. These values are obtained by substituting (3) into (5) and setting profits to zero, as the open access regime is characterized by the dissipation of the economic rent. Thus, the inverse efficiency parameters can be written as $b_{S}^{\min }=X_{S}^{O A} / k$ and $b_{j}=X_{j}^{O A} / k$. These ratios always lie in the range $[0 ; 1]$ as the equilibrium stock levels in open access lie between the minimum of zero (depletion of the stock) and a maximum of the carrying capacity of the ecosystem (no harvest), $k$. 
From (9) and (10) it is evident that best reply functions are downward sloping with a slope less than 1 in absolute terms. Hence, fishing efforts are strategic substitutes in this fishing game. Considering only interior solutions and solving (9) and (10) simultaneously, the unique equilibrium fishing efforts (because best reply functions are contractions) are given by:

$$
\begin{aligned}
& E_{S}^{*}(S)=\frac{(n-m+1) r}{(n-m+2) q}\left(1-b_{S}^{m i n}\right)-\frac{r}{(n-m+2) q} \sum_{j \notin S}\left(1-b_{j}\right) \\
& E_{j}^{*}(S)=\frac{(n-m+1) r}{(n-m+2) q}\left(1-b_{j}\right)-\frac{r}{(n-m+2) q}\left[\left(1-b_{S}^{\text {min }}\right)+\sum_{k \neq j \notin S}\left(1-b_{k}\right)\right]
\end{aligned}
$$

where $n$ is the total number of players and $m$ the number of RFMO members. In order to ensure strictly positive fishing efforts according to (11) and (12) all $b_{i}$ 's must be strictly smaller than 1. Moreover, it can be show that a sufficient condition for strictly positive fishing efforts for all possible coalition structures is (see Appendix 1):

$$
b_{l}+\sum_{k \neq l}\left(b_{l}-b_{k}\right)<1, b_{l}=\max \left\{b_{1}, \ldots, b_{n}\right\} .
$$

Considering that the $b_{i}$ 's only differ because of different cost parameters, this essentially means that cost parameters cannot be too dispersed in an interior solution. That is, in our model the $n$ players are active fishing states; other states simply do no fish as their costs are to high.

Using (11) and (12), the total fishing effort (14) is given by:

$$
E^{*}(S)=E_{S}^{*}(S)+\sum_{j \neq S} E_{j}^{*}(S)=\frac{r}{(n-m+2) q}\left[\left(1-b_{S}^{\min }\right)+\sum_{j \neq S}\left(1-b_{j}\right)\right] .
$$

Upon substitution of (14) into (4) the steady-state fishing stock level is obtained.:

$$
X^{*}(S)=k\left[1-\frac{1}{n-m+2}\left(\left(1-b_{S}^{\min }\right)+\sum_{j \notin S}\left(1-b_{j}\right)\right)\right] .
$$

Finally, equilibrium payoffs of coalition $S$ and singleton $j$ (using (5)) are given by: 


$$
\begin{aligned}
& \Pi_{S}^{*}(S)=\frac{r p k}{(n-m+2)^{2}}\left(1-(n-m+1) b_{S}^{m i n}+\sum_{j \notin S} b_{j}\right)^{2} \\
& \Pi_{j \notin S}^{*}(S)=\frac{r p k}{(n-m+2)^{2}}\left(1-(n-m+1) b_{j}+b_{S}^{m i n}+\sum_{k \neq j \notin S} b_{k}\right)^{2} .
\end{aligned}
$$

We now turn to analyze some economic fundamentals of our model.

\subsection{Economic Fundamentals and Impacts of Different Coalition Structures}

In this section, we first look at some economic fundamentals in order to deepen our understanding of the bioeconomic model. Then we look at the effects on different players due to a change in the coalition structure. This will help to explain some of the results in section 4 related to the incentives to form coalitions and their stability. The analysis presumes that some coalition has formed out of the $2^{n}$ possible coalitions in the first stage.

We first analyze how exogenous changes of the parameters of the bioeconomic model affect the equilibrium fishing stock and the equilibrium payoffs of players. This leads to the following proposition. ${ }^{8}$

\section{Proposition 1: Impact of Parameter Variations}

A change of the parameters of the bioeconomic model $\left(c_{s}^{\min }=\right.$ unit cost of the RFMO, $c_{j}=$ unit cost of a non-member of the RFMO, $p=$ price of fish, $q=$ catchability coefficient, $k=$ carrying capacity and $r$ =intrinsic growth rate of the fish stock) has the implications summarized in Table 1.

\section{Table 1 about here}

The first five parameters in the first column of Table 1 may be viewed as those that determine the economic environment in which fishing states operate, and the last two as those that

8 As the proof of Proposition 1 only requires to study the signs of the derivatives it is not given here. It is available upon request from the authors. All other proofs are provided in the Appendix. 
determine the ecological environment. There are at least three main results which we think should receive particular attention.

1) The ecological implications - measured as a change of the equilibrium stock - are clearcut and are well in line with economic intuition. An increase in the unit cost of either the RFMO or a non-RFMO member leads to a downward adjustment of fishing efforts of the affected party. This primary effect dominates the secondary effect of an expansion of fishing efforts by non-affected parties and hence the aggregate fishing effort decreases and the fish stock increases. A uniform increase of all unit costs $C_{i}$, a decrease of price $p$, and a decrease of the catchability coefficient $q$ makes fishing less attractive and hence will increase the equilibrium fish stock. An increase in the carrying capacity, $k$, and the intrinsic growth rate, $r$, imply on the one hand a higher "restoration capacity" of the ecological system and, on the other hand, higher incentives to expand equilibrium fishing efforts. In our setting, the first effect dominates the second effect in the case of $k$ whereas both effects cancel out for $r$.

2) If the unit cost of the RFMO, $c_{s}^{\min }$, or a non-member, $c_{j}$, decreases, this has a positive effect on own payoffs but a negative effect on the payofss of all other players. This is because fishing efforts are strategic substitutes and all players compete for the fish stock. The net effect at the aggregate cannot be generally predicted, however is negative if all players are symmetric before the change of cost. Predictions are also possible if all unit cost increase equally as this affects all players negatively.

3) It is striking, though not surprising, given the multiple channels through which exogenous changes of parameters affect equilibrium payoffs that no clear-cut predictions are possible for the other parameters (i.e. the effect may be positive or negative) if we do not impose any restriction on the type of asymmetry of players, except for the case of a change of the intrinsic growth rate $r$. This clearly underlines the fact that conclusions derived from the 
assumption of symmetric players do not always carry over to the more general case of heterogeneous players. In the case of symmetric players, all effects are in line with intuition: a higher price, catchability coefficient, carrying capacity and intrinsic growth rate make fishing more attractive and hence have a positive effect on the payoffs of all players.

The next proposition looks at the phenomenon known in the literature on fisheries as the "new entrant problem" (Kaitala and Munro, 1997, Pintassilgo and Costa Duarte, 2001, and McKelvy et al., 2003).

\section{Proposition 2: New Entrant Problem}

Suppose a new player $i$ enters the fishing game such that the number of active players increases from $n$ to $n^{\prime}=n+1$.

a) If the new player acts as a singleton, the equilibrium stock $X^{*}(S)$, the equilibrium payoff of all current non-members $\Pi_{j}^{*}(S)$, as well as the equilibrium coalitional payoff $\Pi_{S}^{*}(S)$ decreases.

b) If the new player joins coalition $S$, forming $S^{\prime}=S \cup\{i\}$, then the equilibrium stock level will decrease, $X_{S}^{*}(S)>X_{S^{\prime}}^{*}\left(S^{\prime}\right)$, the equilibrium coalitional payoff will increase, $\Pi_{S}^{*}(S)<\Pi_{S^{\prime}}^{*}\left(S^{\prime}\right)$, and the equilibrium payoff of all non-members $j \notin S, S^{\prime}$ will decrease, $\Pi_{j}^{*}(S)>\Pi_{j}^{*}\left(S^{\prime}\right)$, if the new member is more efficient than the most efficient player of coalition $S, b_{i}<b_{S}^{\text {min }}$, and will leave them all unaffected otherwise $\left(b_{i} \geq b_{S}^{\text {min }}\right)$.

The new entrant may be seen as a previously inactive fishing state which decides now to enter the "game". This may be because the relative costs of fishing (i.e. opportunity costs) or absolute costs of this state have decreased, making fishing now attractive. This potential entrant increases the competition for the fish stock.

If the new entrant does not join the RFMO and therefore behaves as a singleton, this has a negative impact on all current fishing states, regardless whether they have joined the RFMO or not (Proposition 2a). However, if the new entrant decides to join the RFMO, effects depend 
on its production technology (Proposition 2b). If the new entrant is less efficient than the most efficient RFMO member, nothing changes. Of course, the fact that $\Pi_{S}^{*}(S)$ does not change simply means that current RFMO members have to share their rent with one more member which is not in their interest. However, the alternative that the new entrant remained outside their RFMO would decrease their total rent. Which of the two options is preferred by the current RFMO members is not clear, though not an issue at stake in the context of open membership as entry cannot be prevented.

If the new entrant is more efficient than the most efficient current RFMO member, competition for non-RFMO members increases which decreases their rents. Again the net effect for current RFMO members is not clear (but again not relevant because of open membership) as they have to share a higher economic rent with one more player.

We now study the impacts of an enlargement of the coalition for a given number of players $n$, i.e. if a non-RFMO member joins the RFMO.

\section{Proposition 3: A Non-member joins the RFMO}

Let there be $n$ players. Suppose a non-member $j \notin S$ joins the RFMO such that $S^{\prime}=S \cup\{j\}$.

a)

i) The equilibrium fishing effort of the RFMO will increase, $E_{S}^{*}(S)<E_{S^{\prime}}^{*}\left(S^{\prime}\right)$, as well as those of all non-RFMO members, $E_{j \notin S}^{*}(S)<E_{j \notin S^{\prime}}^{*}\left(S^{\prime}\right)$. The total fishing effort will decrease, $E^{*}(S)>E^{*}\left(S^{\prime}\right)$ and hence the equilibrium stock will increase, $X^{*}(S)<X^{*}\left(S^{\prime}\right)$.

ii) The coalitional payoff will increase, $\Pi_{S}^{*}(S)<\Pi_{S^{\prime}}^{*}\left(S^{\prime}\right)$. The payoff of all non-members, $k \notin S, S^{\prime}, k \neq j$, will also increase, $\Pi_{k}^{*}(S)<\Pi_{k}^{*}\left(S^{\prime}\right)$ (Positive Externality Property - PEP).

b) The aggregate payoff of those players involved in the merger will increase or decrease, $\Pi_{S}^{*}(S)+\Pi_{j}^{*}(S)<>\Pi_{S^{\prime}}^{*}\left(S^{\prime}\right)$ (Superadditivity $\left.-S A D\right)$.

c) The aggregate payoff of all players is strictly higher in the grand coalition, $S=N$, than in any other coalition. 
The intuition of part a) i) is that if player $j$ joins the RFMO, then there is one less free-rider or less competition for the fish stock. Due to negatively sloped best reply functions, the coalition as well as the non-members will adjust their fishing efforts upwards. At the aggregate level, this secondary effect is dominated by the primary effect that the new number will no longer exert non-cooperative fishing efforts. Consequently, starting from the singleton coalition structure and considering a sequence of mergers, the total equilibrium fishing effort will decrease and the equilibrium stock level will increase with the degree of cooperation. Thus, cooperation helps to internalize externalities.

Building on this intuition, part a) ii) suggests that a higher degree of cooperation has a positive effect on the coalitional but also on non-members's payoff. The latter effect is known in the literature on coalition formation as the Positive Externality Property (PEP) (Bloch 2003 and Yi 2003). This effect is the most important driving force why the formation of large stable coalitions proves difficult in the context of a common pool resource as long as nobody can be excluded (Finus 2003). This problem is severe despite the fact that mergers increase the coalitional payoff, but - even more important - despite the fact that the total payoff of all players involved in the mergers may increase, a condition which has been called superadditivity (SAD), and referred to in part b).

On the one hand, even if SAD holds, as long as the PEP-effect is stronger, which tends to occur for large coalitions, free-riding may still be attractive. On the other hand, the free-rider problem is intensified when SAD fails. This failure is not uncommon in coalition formation games and applies to many economic problems (see e.g. Eyckmans and Finus 2004 for an overview). Due to negatively sloped reaction functions the good intentions of the coalition members are obstructed by non-members.

Finally, not surprisingly, part c) states that the aggregate economic rent in the grand coalition, corresponding to the global optimum, is strictly higher than in any other coalition. This 
simply follows from the fact that by assumption the total rent over all players is maximized in the grand coalition (which proves the term "higher") and the equilibrium effort vector $E^{*}(N)$ differs in at least one element from any other coalition $S \neq N$ (which proves the term "strictly") as can be seen from equations (11) and (12).

\section{First Stage of Coalition Formation: Stability and Overall Success}

\subsection{Preliminaries}

Section 3 clarified how the partition function assigns to every coalition $S$ a vector of payoffs or worth, $\Pi: S \mapsto \Pi(S)=\left(\Pi_{S}(S), \Pi_{j}(S)\right)$ in the second stage of the coalition formation process and how these values depend on the model parameters, on a new entrant or a nonmember joining the RFMO. Now we move on to the first stage, analyzing which coalitions are stable.

In the first stage, participation strategies also form a Nash equilibrium. This is characterized by the absence of incentives to change the participation decision, both for RFMO members and non-members:

Internal Stability: $\quad V_{i}(S) \geq V_{i}(S \backslash\{i\}) \quad \forall i \in S$

External Stability: $\quad V_{j}(S) \geq V_{j}(S \cup\{j\}) \quad \forall j \notin S$

where we assume that there is some valuation function (which has also been called permembership partition function; e.g. Bloch 2003) which maps the aggregate payoff or worth into valuations such that $\Pi_{S}(S)+\sum_{i \notin S} \Pi_{i \notin S}(S)=\sum_{i \in N} V_{i}(S)$. This means that valuations add up to the total worth of the game and there are no resources outside it.

The analysis based on individual payoffs, implied by the valuation function, requires some assumption about the sharing rule. Strictly speaking, though often neglected, this would even be true if we assumed equal sharing for symmetric players. Though it may seem obvious, this 
is nevertheless an assumption. In the following, we show that for the present game the analysis can be based on very general assumptions.

Firstly, let us concentrate on internal stability as this is the most important dimension when analyzing free-rider problems in our context. Assume that the coalitional payoff is only shared among its members, i.e. $\Pi_{S}(S)=\sum_{i \in S} V_{i}(S)$, and $\Pi_{i \notin S}(S)=V_{i \notin S}(S)$. Using condition (18) and summing over all members of coalition $S$ we obtain:

$\Pi_{S}(S) \geq \sum_{i \in S} \Pi_{i}(S \backslash\{i\})$

Condition (20) has been termed potentially internally stability (PIS) by Eyckmans and Finus (2004). As already noted by Pintassilgo (2003), if PIS holds, then there exists some sharing rule which makes coalition $S$ internally stable. We can also conclude that, whenever PIS fails, internal stability fails regardless of the sharing rule. This suggests that internal stability can be analyzed without prior assumptions about the sharing scheme.

Secondly, consider external stability in (19). Clearly, in an open membership it does make sense to look for a similar condition which could be called potential external stability. However, suppose we invoke the sharing scheme proposed by Eyckmans and Finus (2004) and Weikart (2005) which gives every player in coalition $S$ its free-rider payoff plus a share $\lambda_{i}(S)$ of the surplus of the coalitional payoff over the sum of free-rider payoffs $\Delta(S)$ :

$$
\begin{aligned}
V_{i}(S)=\Pi_{i}(S \backslash\{i\})+\lambda_{i}(S) \Delta(S) ; \Delta(S)=\Pi(S)-\sum_{i \in S} \Pi_{i}(S \backslash\{i\}), \\
\\
\quad \sum_{i \in S} \lambda_{i}(S)=1, \lambda_{i}(S)>0, \forall i \in S .
\end{aligned}
$$

It is easy to see that whenever condition (20) holds, i.e. coalition $S$ is PIS, then this sharing scheme makes $S$ internally stable, irrespective of weights $\lambda_{i}$. If, on the contrary, coalition $S$ is not PIS (hence $\Delta(S)<0$ ), there are no weights that make $S$ internally stable. Moreover, (21) allows us to establish a direct link between internal and external stability: if coalition $S$ 
is not PIS, then all coalitions $S \backslash\{i\}$ for all $i \in S$ are externally stable, irrespective of weights. Consequently, both the sets of internally and externally stable coalitions (and hence the set of stable coalitions) are independent of weights. Moreover, it means that we can infer external stability from PIS.

Thirdly, as Carraro et al. (2006) prove, given sharing scheme (21), every stable coalition cannot be enlarged by coalition members persuading non-members to join through the use of transfers. The intuition is simple. If coalition $S$ is stable, every coalition $S \cup\{j\}$, for all $j \notin S$, is not PIS which is a necessary condition for this strategy to be successful.

Summarizing, by assuming the general sharing scheme in (21) we determine the largest stable coalitions. We can neglect transfers between the RFMO and outsiders earmarked to enlarge a coalition. Checking PIS allows to infer internal and external stability and hence stability. PIS always holds for the trivial coalition structure in which all players behave as singletons $(m=1)$ as no player can deviate further. For all other cases $(m \geq 2)$, PIS-condition (20) has to be analyzed. Using equilibrium payoffs (16) and (17), this condition can be written as:

$$
\left(\frac{n-m+3}{n-m+2}\right)^{2}\left(1-(n-m+1) b_{S}^{\min }+\sum_{j \notin S} b_{j}\right)^{2} \geq \sum_{i \in S}\left(1-(n-m+2) b_{i}+b_{S^{\prime}}^{\min }+\sum_{k \neq i \notin S^{\prime}} b_{k}\right)^{2}
$$

where $S^{\prime}=S \backslash\{i\}$ and $b_{S^{\prime}}^{\min }$ is the lowest $b$ in coalition $S^{\prime}$. The interesting aspect of this condition is that, for a given number of players $n$, and coalition size $m$, potential internal stability only depends on the vector $b=\left(b_{1}, \ldots, b_{n}\right)$ where we may recall that $b_{i}=c_{i} / p q k$, $0 \leq b_{i} \leq 1$.

In the case of symmetric players, Pintassilgo and Lindroos (forthcoming) have shown that (22) can only be satisfied if and only if $n=m=2$. Thus for any larger number of players only the singleton coalition structure is stable. Hence, it is important to test whether this also holds in the context of asymmetric players. As we do no want to impose any restriction on the 
asymmetry of players (except that parameter restriction (13) must hold for an interior solution), we have to resort to simulations which are described in the next section.

\subsection{Simulation Method}

\subsubsection{Introduction}

The use of simulation methods in the stability analysis of fisheries and international environmental agreements was recently introduced in the literature (Kronbak and Lindroos 2006). Also Dellink et al. (forthcoming) analyze stability of agreements reducing greenhouse gases in the context of uncertainty, using Monte Carlo simulations to estimate the probability of a given coalition being stable, which they call stability likelihood.

This paper also estimates the stability likelihood of different coalition structures. Furthermore, we compute indexes that measure the success of coalition formation. For this it is assumed that the inverse efficiency parameters are uniformly distributed, $b_{i} \square U(0,1), \forall i \in\{1, \ldots, n\}$. We opt for this distribution because of its simplicity and the fact that it is completely defined by the parameter range. An algorithm for Monte Carlo simulations is programmed using the software package Matlab, incorporating the restriction of strictly positive fishing effort (13). The simulation of the vector $b$ was repeated whenever the restriction was violated.

\subsubsection{Stability Likelihood}

According to (22), internal stability of a $m$-size coalition, for a given number of players $n$, is completely determined by the vector $b$. Simulating a large number of vectors $b$ allows to estimate the probability of a random $m$-size coalition being internally stable, i.e. its internal stability likelihood (ISL), hereafter denoted by $\theta$. This parameter as well as the other following probabilities are estimated through the "sampling proportion". In the case of ISL, this is $\hat{\theta}=Y / n s i m$ where $n$ sim denotes the number of simulations and $Y$ the number of times 
a random $m$-size coalition is internally stable in those simulations. This is an unbiased estimator and also the maximum likelihood estimator for $\theta$.

A total of 50,000 simulations are undertaken. As the standard deviation of the estimator is given by $\sigma(\hat{\theta})=\sqrt{\frac{\theta(1-\theta)}{n \operatorname{sim}}}$, the maximum value is only $\sigma(\hat{\theta}) \square 0.002$, which occurs for $\theta=0.5$. Furthermore, generally, the central limit theorem applies to $\hat{\theta}$ and hence it follows approximately a normal distribution. ${ }^{9}$ Therefore, the maximum margin of error for confidence intervals can be computed. For instance, the maximum margin of error of a $95 \%$ confidence interval is only about 0.004 . Hence, the high number of simulations guarantees a very low margin of error for the estimated probabilities.

The probability of a random $m$-size coalition being externally stable, i.e. its external stability likelihood (ESL), was also estimated. As pointed out in section 4.1, external stability is linked to internal stability through sharing scheme (21). Hence, coalition $S$ is externally stable if all coalitions $S \cup\{j\}$ are not PIS, i.e., the surplus $\Delta(S \cup\{j\})$ is negative. Since PIS and hence the surplus only depends on the vector $b$, it is possible to determine directly external stability for each vector. Following the same procedure to estimate ISL, ESL of a random $m$-size coalition was estimated as the proportion of externally stable coalitions over all samples. Finally, the probability of a random $m$-size coalition being stable, i.e. its stability likelihood (SL), is estimated as the proportion of coalitions that are simultaneously internally and externally stable in the simulations.

9 Using the rule of thumb that $(n \operatorname{sim}) \theta>5$ and $(n \operatorname{sim})(1-\theta)>5$ (Lind et al. 2005), it applies for all $\theta$ in the range $[0.0001 ; 0.9999]$. 


\subsubsection{Overall Success Indexes}

We consider two relative welfare measures. The first is called the Social Gain Index (SGI) and is a measure of the relative gain from cooperation that could be obtained if the grand coalition formed and is defined as follows:

$$
S G I(b, n)=\frac{\Pi(N)-\sum_{i=1}^{n} \Pi_{i}\left(1_{(n)}\right)}{\Pi(N)}
$$

where $\Pi(N)$ represents the aggregate payoff of the grand coalition and $\sum_{i=1}^{n} \Pi_{i}\left(1_{(n)}\right)$ the aggregate payoff when all players are singletons.

As the vector $b$ is simulated over a uniform distribution, the expected value of this index, $E(\operatorname{SGI}(n))$, is estimated as the average over all samples:

$\overline{S G I}(n)=\frac{\sum_{\ell=1}^{n s i m} S G I(b(\ell), n)}{n \operatorname{sim}}$

where nsim represents the number of simulations.

The second index is called the Closing the Gap Index (CGI) and is a measure of the relative gain from cooperation obtained by stable coalitions. It is a measure of how much stable equilibria succeed in closing the gap between full cooperation and no cooperation. For a given stable coalition $\left(S_{j}^{*}\right)$ this index is defined as:

$$
C G I\left(S_{j}^{*}(b), n\right)=\frac{\left(\Pi_{S_{j}^{*}}\left(S_{j}^{*}\right)+\sum_{i \notin S_{j}} \Pi_{i}\left(S_{j}^{*}\right)\right)-\sum_{i=1}^{n} \Pi_{i}\left(1_{(n)}\right)}{\Pi(N)-\sum_{i=1}^{n} \Pi_{i}\left(1_{(n)}\right)} .
$$

Assuming that all stable equilibria are equally likely, for a given vector $b$, the average $C G I$ index can be computed as the average of the values obtained for each equilibrium: 
$\operatorname{CGI}(b, n)=\frac{\sum_{j=1}^{n s c(b)} \operatorname{CGI}\left(S_{j}^{*}(b), n\right)}{n s c(b)}$

where $n s c(b)$ represents the number of stable coalitions for a given vector $b$. Finally, the expected value of $C G I, E(C G I(n))$, is estimated as the average value over all generated samples:

$\overline{C G I}(n)=\frac{\sum_{\ell=1}^{\text {nsim }} C G I(b(\ell), n)}{n \operatorname{sim}}$.

Both $\overline{S G I}(n)$ and $\overline{C G I}(n)$ are the natural estimators of the expected values of both indexes as they are unbiased and the maximum likelihood estimators. Furthermore, the high number of simulations used $(n \operatorname{sim}=50,000)$ guarantees a low standard deviation of these estimators.

\subsection{Simulation Results: Base Case}

In this section, we analyze simulation results of what we call the base case. That is, each element of the vector $b$ is uniformly distributed in the range [0;1]. Table 2 displays the estimates of internal stability likelihood for 2 to 10 players. Recall that the singleton coalition is stable by definition. Hence, all diagonal elements in Table 2 show probability 1.

\section{Table 2 about here}

\section{Result 1}

For a given number of players, $n$, internal stability likelihood decreases with the number of coalition members, $m$.

Result 1 compares probabilities within columns. This shows that free-rider incentives increase with the coalition size. According to Proposition 3, an increase of the coalition size produces two opposite effects on the coalitional surplus, which is the difference between the coalitional payoff and the sum of the free-rider payoffs. On the one hand, the coalitional payoff increases with the number of RFMO members, though the aggregate payoff of those players involved in 
the enlargement may not necessarily increase, i.e. superadditivity may fail to hold. On the other hand, it also increases the sum of free-rider payoffs, both because of a higher number of potential free-riders in the enlarged coalition, and an increase of the free-rider payoffs of the original members due to the positive externality effect. The results show that this second effect is stronger. Note that the case of $n=2$ is an exception. In this particular case saying that the grand coalition is potential internal stability is equivalent to saying that the grand coalition generates a strictly higher aggregate payoff than in any other coalition (Proposition $3 c)$.

\section{Result 2}

Internal stability likelihood of a coalition with $m=n-k$ members, $k=\{0, \ldots, n-1\}$, decreases with the number fishing states $n$.

Result 2 compares probabilities within rows. From Table 2 it is evident that the probability of the grand coalition being internally stable decreases with the number of players. Already for seven players internal stability likelihood is zero in the example. In other words, for a not too small number of fishing states it is very unlikely that a stable RFMO comprises all members (as internal stability is a necessary condition for stability). However, also for smaller coalitions the likelihood of internal stability decreases with the number of fishing states. This may be interpreted as follows: the more intense is the competition for the fish stock, the more unlikely it is that a RFMO of particular size is internally stable.

Comparing rows for a given number of coalition members $m=n-k$ can be related to the "new member problem" mentioned in Proposition 2b. Accordingly, when a new entrant joins the coalition, this increases or leaves the coalitional payoff unaffected and decreases or leaves the payoff of the singletons, and also free-riders, unaffected. Nevertheless, theoretical predictions about internal stability are not straightforward for at least two reasons. Firstly, even if the coalitional payoff increases it has to be shared with one more member. Secondly, even if the free-rider payoffs of the original coalition members decrease, there is now one 
more potential free-rider and hence the sum of free-rider payoffs may increase. According to the simulations, the sum of free-rider payoffs increases more than the coalitional payoff causing internal stability likelihood of a coalition with $m=n-k$ members to decreases with $n$.

Turning now to external stability (see Table 3) we notice that this is basically the mirror image of internal stability. This is due the link between internal and external stability introduced by the general transfer scheme (21).

\section{Table 3 about here}

\section{Result 3}

For external stability Results 1 and 2 are reversed.

For a given number of players, external stability likelihood increases with the number of players (comparison within a column). That is, it becomes less attractive for non-RFMO members to join the RFMO. Furthermore, for a given number of singletons, $k$, external stability likelihood increases with the number of players, $n$ (comparison within rows).

Finally, simulation results on stability, which comprises both internal and external stability, are displayed in Table 4. As internal stability decreases within a column from the top to the bottom entry and decreases within a row from the very left to the very right entry (see Table 2), and just the opposite holds for external stability (see Table 3), it is not surprising that the regular patterns observed above in Tables 2 and 3 are not found in Table 4. Nevertheless, the results in Table 4 can be summarized as follows.

\section{Table 4 about here}

\section{Result 4}

For a sufficiently large number of fishing states (e.g. $n \geq 5$ ) the stability likelihood of a RFMO with a significant number of fishing states (e.g. $m \geq n-3$ ) is small and tends sharply to zero as $n$ increases. 
This result confirms an observation already made for internal stability: in the presence of a sufficiently fierce competition for the fish stock, the formation of a RFMO of a size that can make a noticeable difference to the overfishing of the stock is very unlikely. Only in fisheries characterized by few harvesting states, i.e. two or three, is the formation of a stable RFMO involving all states a likely outcome. This is compactly summarized by our two indexes (see section 4.2 for a definition). On the one hand, the estimates of $E(S G I(n)), \overline{S G I}(n)$, measuring the relative difference between the global optimum (i.e. full cooperation) and the Nash equilibrium (i.e. no cooperation) increase with the number of fishing states. In other words, the more states engaged in fishing, the more prompting would be the need for cooperation. On the other hand, with an increasing number of fishing states the success of cooperation declines as measured by the estimates of $E(C G I(n)), \overline{C G I}(n)$. In the next section we will test the robustness of this conclusion.

\subsection{Simulation Results: The Asymmetry and Efficiency Effect}

In this section, we analyze two effects: the asymmetry and the efficiency effect. In order to isolate the effect of asymmetry, we run simulations for different ranges of each element of the uniformly distributed vector $b$ (implying different standard deviations) but with the same expected value: $E\left(b_{i}\right)$. Given the definition of $b_{i}=c_{i} / p q k$, the larger its standard deviation, the more states differ in terms of unit production costs $c_{i}$. A representative example includes the estimates of $E(S G I(n))$ and $E(C G I(n))$, for $b_{i}=0.2$ (no asymmetry), $b_{i} \in[0.1 ; 0.3]$ and $b_{i} \in[0 ; 0.4]$ for all $i \in N$ in Table 5 . The result can be summarized as follows.

\section{Result 5}

For given number of players $n>2$ and $E\left(b_{i}\right), E(C G I(n))$ increases with the range of the parameters $b_{i}$, i.e. the degree of asymmetry. 
This result suggest that the success of coalition formation is positively correlated with the degree of cost asymmetry among fishing states. The significance of this result gains even more momentum by recalling from section 4.1 that in the case of symmetric players no RFMO would be stable for $n>2$. Hence, as long as $n>2$, CGI would always be zero for symmetric players irrespective of the value of the parameters $b_{i}$. In other words, asymmetry is not an obstacle but conducive to the stability and success of establishing a RFMO.

The simplest explanation of this striking result is that with heterogeneous players the success rate of coalition formation can almost not be worse than in the benchmark case of symmetric players. A more elaborate explanation suggests that the larger the cost asymmetries, the larger are the gains from cooperation. Not only does the coalition internalize the externality within the RFMO (which also applies to symmetric players), but it also exploits the gains from a cost-effective allocation of fishing efforts (which increase with the degree of cost asymmetry). Due to sharing scheme (21), these gains transform into more successful coalitions. ${ }^{10}$

In order to isolate the effect of efficiency, we run simulations for different $E\left(b_{i}\right)$ but with the same range (and hence same standard deviation). The higher $E\left(b_{i}\right)$, the lower the overall efficiency. Table 5 shows estimates of $E(S G I(n))$ and $E(C G I(n))$ for a representative example: $b_{i} \in[0 ; 0.2], b_{i} \in[0.2 ; 0.4]$ and $b_{i} \in[0.4 ; 0.6]$, implying that $E\left(b_{i}\right)$ increases from 0.1 to 0.3 , reaching finally 0.5 . The results can be summarized as follows.

\section{Result 6}

For a given number of players $n>2$, and given range of the parameters $b_{i}, E(C G I(n))$ increases with $E\left(b_{i}\right)$, i.e. the level of inefficiency.

10 This explanation has been pointed out to us by H.-P. Weikart. See also Weikart (2005). 
According to this result the lower the efficiency level, or equivalently the higher the $E\left(b_{i}\right)$, the higher $E(C G I(n))$. Given that $b_{i}=c_{i} / p q k$, a uniform increase of this parameter for all players can be due to a uniform increase in the unit cost $c_{i}$, a decrease in the price $p$, the catchability coefficient $q$ or the carrying capacity of the ecosystem $k$. According to Proposition 1, a change of these parameters in this direction reduces the total fishing effort as fishing becomes less attractive. Hence, competition for the fish stock is lower, making it easier to form larger stable coalitions. Finally, looking at Tables 4 and 5 together shows a robust result.

\section{Result 7}

For a given range of the parameters $b_{i}, E(S G I(n))$ increases and $E(C G I(n))$ decreases with the number of players.

That is, the larger the relative gap between social optimum and Nash equilibrium, $E(S G I(n))$, which increases with the number of players engaging in fishing, the lower is the relative average success of forming stable RFMOs. Hence, the paradox of the global commons, which has first been described for global emissions by Barrett (1994), also applies to international fisheries: whenever cooperation would be most needed, it achieves only little.

\section{Summary and Conclusions}

This paper analyzed the formation, stability and success of Regional Fisheries Management Organizations (RFMOs) in managing straddling fish stocks. For this the classical GordonSchaefer bioeconomic model was linked a coalition formation model. In the first stage, fishing states decide whether to join the RFMO or to remain outside. In the second stage, RFMO members coordinate their fishing efforts whereas non-members behave non- 
cooperatively. The game is solved backward, requiring that strategies form a Nash equilibrium in each stage. A central and new feature of our model is the differences in unit costs of harvesting across fishing states.

The effects of an exogenous change of the parameters of the model, as well as the number of players and the coalition size, on the fish stock and the payoffs of players - affecting their incentives to participate in a RFMO - could be derived analytically. In contrast, in analyzing the implications for stability and the overall success of RFMOs, it was necessary to rely on Monte Carlo simulations which showed a clear-cut and robust pattern. Among the many results forthcoming from the analysis, we would like to highlight three.

1) The larger the number of fishing states that compete for the fish stock, the higher are the relative gains from full cooperation, but the lower is the likelihood that large RFMOs are stable and their relative success of closing the gap between full and no cooperation. The number of fishing states includes those currently actively engaging in fishing which may change if a previously non-active state decides either to join the RFMO or to behave noncooperatively. This paradox is due to the fact that RFMO members cannot exclude nonmembers from harvesting the fish stock. RFMO endeavors are contradicted by non-members, as fishing efforts are strategic substitutes. The larger the RFMO, the more non-members benefit from the cooperative management efforts of the RFMO, which reduces their incentive to join the RFMO. This result is in line with empirical findings on the success of various RFMOs surveyed in Bjørndal and Martin (2007) who conclude (p. 35): “The larger the number of actual and potential players, the more difficult it is to achieve a cooperative solution, and the greater the incentive for some players to free-ride".

2) The higher the overall efficiency of all fishing states in harvesting, the lower the relative success of coalition formation. In our model, a high efficiency was related to either low unit production costs, a high market price for fish, a high catchability coefficient or a high 
carrying capacity of the ecological system. All this makes fishing attractive; increasing the competition for the fish stock, but is detrimental to the formation of stable RFMOs that successfully manage to preserve the fish stock at high levels. This suggests that the rapid technological progress in harvesting straddling fish stocks that took place over the last two decades (High Seas Task Force 2006) may also have been pivotal for the difficulties in forming stable RFMOs.

3) The higher the cost asymmetry among fishing states, the higher the relative success of RFMOs. This result only assumed a very general sharing scheme of the gains from cooperation and - to the best of our knowledge - has not been shown before. At first thought one would have expected that asymmetry would make coalition formation more difficult. However, it then became clear that cost asymmetries increase the potential gains from cooperation through a cost-effective allocation of fishing efforts. This potential is fully exploited in our model through the optimal sharing scheme that we applied. An important implication of this "optimistic" result is that cost asymmetries, e.g. between costal and distant water fishing states, may not be an obstacle to the formation of cooperative agreements but, on the contrary, can foster it.

The overall conclusion is that, if the international fishing community does prove to be incapable of suppressing unregulated fishing, the outlook for the emerging RFMO regime is bleak. Our findings are in line with a recently released report by an international panel of experts on RFMOs, which states that "the success of international [fisheries] cooperation depends largely on the ability to deter free riding" (Lodge, et al., 2007, p. x)

This paper opens at least two avenues for further research. Firstly, the model can be used to analyze in more detail institutional and legal measures to curb unregulated fishing. Secondly, the model could be generalized to a dynamic bioeconomic model which explicitly models the migration of the fish stock and extends asymmetry to other model parameters. 


\section{References}

d'Aspremont, C., A. Jacquemin, J.J. Gabszewicz and J.A. Weymark (1983). On the Stability of Collusive Price Leadership. Canadian Journal of Economics, vol. 16(1), 17-25.

Barrett, S. (1994). Self-enforcing International Environmental Agreements. Oxford Economic Papers, vol. 46, 878-894.

Bjørndal and Martin (2007). Recommended Best Practices for Regional Fisheries Management Organizations - Technical Study No. 3. The Relevance of Bioeconomic Modelling to RFMO Resources: A Survey of the Literature. London: Chatham House.

Bloch, F. (2003). Non-cooperative Models of Coalition Formation in Games with Spillovers. In: Carraro, C. (ed.). The Endogenous Formation of Economic Coalitions. Cheltenham: Edward Elgar, ch. 2, 35-79.

Carraro, C. (2000), Roads Towards International Environmental Agreements. In: Siebert, H. (ed.), The Economics of International Environmental Problems. Mohr Siebeck, Tübingen, 169-202.

Carraro, C., J. Eyckmans and M. Finus (2006). Optimal Transfers and Participation Decisions in International Environmental Agreements. Review of International Organizations, vol. 1 (4), 379-396.

Clark, C. and G. Munro (1975). The Economics of Fishing and Modern Capital Theory: A Simplified Approach. Journal of Environmental Economics and Management, vol. 2, 92-106.

Dellink, R., M. Finus, N. Olieman (forthcoming), Coalition Formation under Uncertainty: The Stability Likelihood of an International Climate Agreement. Environmental and Resource Economics.

Eyckmans, J. and M. Finus (2004). An Almost Ideal Sharing Scheme for Coalition Games with Externalities. Working Paper No. 155.2004, Fondazione Eni Enrico Mattei, Italy. Current version as presented at the 7th Meeting on Game Theory and Practice Dedicated to Energy, Environment and Natural Resources, May 2007, Montreal, Canada.

Finus, M. (2003). Stability and Design of International Environmental Agreements: The Case of Global and Transboundary Pollution. In: Folmer, H. and T. Tietenberg (eds.), International Yearbook of Environmental and Resource Economics 2003/4. Cheltenham: Edward Elgar, ch. 3, 82-158.

Gordon, H. (1954). The Economic Theory of a Common Property Resource: the Fishery, Journal of Political Economy, vol. 62, 124-142.

Haeringer, G. (2004). Equilibrium Binding Agreements: A Comment. Journal of Economic Theory, vol. 117, 140-143.

Hannesson, R. (1997). Fishing as a Supergame. Journal of Environmental Economics and Management, vol. 32, 309-322. 
High Seas Task Force (2006). Closing the Net: Stopping Illegal Fishing on the High Seas. Government of Australia, Canada, Chile, Namibia, New Zealand, and the United Kingdom, WWF, IUCN and the Earth Institute at Columbia University.

Kaitala, V. and G. Munro (1997). The Management of High Seas Fisheries. Natural Resource Modeling, vol. 10, 87-108.

Kennedy, J. (2003). Scope for Efficient Multinational Exploitation of North-East Atlantic Mackerel. Marine Resource Economics, vol. 18, 55-80.

Kronbak, L. and M. Lindroos (2006). An Enforcement-Coalition Model: Fishermen and Authorities Forming Coalitions. Environmental \& Resource Economics, vol. 35, 169-194.

Kwon, O. (2006). Partial International Coordination in the Great Fish War. Environmental \& Resource Economics, vol. 33, 463-483.

Lind, D. A., W.G. Marchal and S. A. Wathen (2005). Statistical Techniques in Business \& Economics, McGraw-Hill (twelfth edition).

Lindroos, M. (2004). Sharing the Benefits of Cooperation in the Norwegian Spring-spawning Herring. International Game Theory Review, vol. 6 (1), 35-53.

Lindroos, M. (forthcoming). Coalitions in International Fisheries Management. Natural Resource Modeling.

Lodge, M., D. Anderson, T. Lǿbach, G. Munro, K. Sainsbury and A. Willock (2007). Recommended Best Practices for Regional Fisheries Management Organizations: Report of an Independent Panel to Develop a Model for Improved Governance by Regional Fisheries Management Organizations. London: Chatham House.

McKelvey, R., L. Sandal and S. Steinshamn (2003). Regional Fisheries Management on the High Seas: the Hit-and-run Interloper Model. International Game Theory Review, vol. 5 (4), 327-345.

Mesterton-Gibbons, M. (1993). Game-theoretic Resource Modeling. Natural Resource Modeling 7 (2), 93-147.

Munro, G., A. Van Houtte and R. Willmann, R. (2004): The Conservation and Management of Shared Fish Stocks: Legal and Economic Aspects, FAO Fisheries Technical Paper No. 465, Rome.

Pham Do, K. \& Folmer, H. (2006). International Fisheries Agreements: the Feasibility and Impacts of Partial Cooperation. In: Aronsson, T., R. Axelsson, and R. Brännlund (eds.), The Theory and Practice of Environmental and Resource Economics. Cheltenham: Edward Elgar, 146-172.

Pintassilgo, P. (2003). A Coalition Approach to the Management of High Seas Fisheries in the Presence of Externalities. Natural Resource Modeling, vol. 16 (2), 175-197. 
Pintassilgo, P. and C. Costa Duarte (2001). The New-Member Problem in the Cooperative Management of High Seas Fisheries. Marine Resource Economics, vol. 15, 361-378.

Pintassilgo, P. and M. Lindroos (forthcoming). Coalition Formation in Straddling Stock Fisheries: a Partition Function Approach. International Game Theory Review.

Ruseski, G. (1998). International Fish Wars: the Strategic Roles for Fleet Licensing and Effort Subsidies. Journal of Environmental Economics and Management, vol. 36, 70-88.

Tarui, N., C. Mason, S. Polasky and G. Ellis (2008). Cooperative in the Commons with Unobservable Actions. Journal of Environmental Economics and Management, vol. 55, 37 51 .

United Nations (1982). United Nations Convention on the Law of the Sea. UN Doc. A/Conf.62/122.

(1995). United Nations Conference on Straddling Fish Stocks and Highly Migratory Fish Stocks. Agreement for the Implementation of the Provisions of the United Nations Convention on the Law of the Sea of 10 December 1982 Relating to the Conservation and Management of Straddling Fish Stocks and Highly Migratory Fish Stocks, UN Doc. A/Conf./164/37.

Weikard, H.-P. (2005), Cartel Stability under Optimal Sharing Rule. Working Paper 77. 2005, Fondazione Eni Enrico Mattei, Italy.

Yi, S.-S. (2003). Endogeneous Formation of Economic Coalitions: a Survey of the Partition Function Approach. In Carraro, Carlo (eds.), The Endogeneous Formation of Economic Coalitions. The Fondazione Eni Enrico Mattei (FEEM) Series on Economics and the Environment. Cheltenham: Edward Elgar, ch. 3, 80-127. 


\section{Appendix I: Derivation of Equations (11), (12) and (13)}

From (9) and (10), strictly positive fishing efforts imply:

$$
\begin{aligned}
& E_{S}=\frac{r}{2 q}\left(1-b_{S}^{\min }\right)-\frac{1}{2} \sum_{j \notin S} E_{j} \\
& E_{j}=\frac{r}{2 q}\left(1-b_{j}\right)-\frac{1}{2}\left(E_{s}+\sum_{k \neq j \notin S} E_{k}\right) .
\end{aligned}
$$

Summing (A2) over all $j \notin S$ gives

$$
\sum_{j \notin S} E_{j}=\frac{r}{q(n-m+1)} \sum_{j \notin S}\left(1-b_{j}\right)-\frac{n-m}{n-m+1} E_{S}
$$

Substituting (A3) into (A1) and solving for $E_{S}$ gives (11) in the text. Applying a similar procedure leads to (12) in the text. A sufficient condition for $E_{S}^{*}(S)>0$ in (11) and $E_{j \notin S}^{*}(S)>0$ in (12) is:

$$
\begin{aligned}
& A=1-(n-m+1) b_{S}^{\min }+\sum_{j \notin S} b_{j}>0 \\
& B=1-(n-m+1) b_{j}+b_{S}^{\text {min }}+\sum_{k \neq j \notin S} b_{k}>0
\end{aligned}
$$

respectively. Both conditions are assumed to hold throughout the paper and will be used frequently in the subsequent proofs. As we show below in Appendix III, $E_{S}^{*}(S)$ and $E_{j \notin S}^{*}(S)$ increase with the number of coalition members, $m$. Moreover, for $m=1, E_{S}^{*}(\{k\})=E_{j}^{*}(\{k\})$ and $E_{j}^{*}(\{k\})>E_{l}^{*}(\{k\})$ if $b_{j}<b_{l}$. Thus, a sufficient condition for strictly positive fishing efforts of all players and for all possible coalition structures is derived by substituting $m=1$ in $B$ and replacing $b_{j}$ by $b_{l}: B=1-n b_{l}+\sum_{k \neq l} b_{k}>0$ with $b_{l}=\max \left\{b_{1}, \ldots, b_{n}\right\}$, which is equivalent to (13) in the text. Hence, condition (13) is a sufficient condition for $A>0$ and $B>0$ to hold. 


\section{Appendix II: Proposition 2}

a) Assume a new player enters the game such that $n^{\prime}=n+1$. Suppose the new player $i$ acts as a singleton, then $m^{\prime}=m$. Let $\Delta X^{*}(S)=X^{*}(S, n)-X^{*}(S, n+1)$. Then, using (15) in the text:

$$
\Delta X^{*}(S)=k\left[1-\frac{1}{n-m+2}\left(\left(1-b_{S}^{\min }\right)+\sum_{j \notin S}\left(1-b_{j}\right)\right)\right]-k\left[1-\frac{1}{n^{\prime}-m^{\prime}+2}\left(\left(1-b_{S}^{\min }\right)+\sum_{j \notin S}\left(1-b_{j}\right)+\left(1-b_{i}\right)\right)\right]
$$

After some manipulation we derive:

$\operatorname{sign}\left(\Delta X^{*}(S)\right)=\operatorname{sign}\left[1-\left(n^{\prime}-m+1\right) b_{i}-b_{S}^{m i n}+\sum_{k \neq i \notin S^{\prime}} b_{k}\right]$

where the term in brackets is condition $B>0$ for $n^{\prime}=n+1$ players and hence $\Delta X^{*}(S)>0$.

Let $\Delta \Pi_{S}^{*}(S)=\Pi_{S}^{*}(S, n)-\Pi_{S}^{*}(S, n+1)$. Then using (16) in the text:

$$
\Delta \Pi_{S}^{*}(S)=\frac{r p k}{(n-m+2)^{2}}\left(1-(n-m+1) b_{S}^{\min }+\sum_{j \notin S} b_{j}\right)^{2}-\frac{r p k}{(n-m+3)^{2}}\left(1-(n-m+2) b_{S}^{\min }+\sum_{j \notin S} b_{j}+b_{i}\right)^{2}
$$

We find after some basic manipulations:

$\operatorname{sign}\left(\Delta \Pi_{S}^{*}(S)\right)=\operatorname{sign}\left[1-\left(n^{\prime}-m+1\right) b_{i}+b_{S}^{\min }+\sum_{j \notin S} b_{j}\right]$

where the term in brackets is $B>0$ for $n^{\prime}=n+1$ players from above and hence $\Delta \Pi_{S}^{*}(S)>0$.

A similar procedure, letting $\Delta \Pi_{j \notin S}^{*}(S)=\Pi_{j \notin S}^{*}(S, n)-\Pi_{j \notin S}^{*}(S, n+1)$ and using (17) in the text, gives:

$$
\operatorname{sign}\left(\Delta \Pi_{j \notin S}^{*}(S)\right)=\operatorname{sign}\left[1-\left(n^{\prime}-m+1\right) b_{i}+b_{S}^{\min }+\sum_{k \neq i \notin S} b_{k}\right]
$$

where the term in brackets is $B>0$ for $n^{\prime}=n+1$ players and hence $\Delta \Pi_{j \notin S}^{*}(S)>0$. 
b) Again, assume a new player enters the game such that $n^{\prime}=n+1$. Suppose the new player $i$ joins coalition $S$ such that $S^{\prime}=S \cup\{i\}$, then $m^{\prime}=m+1$. If $b_{i}<b_{S}^{\min }$, then $b_{S^{\prime}}^{\min }=b_{i}$ and if $b_{i} \geq b_{S}^{\min }$, then $b_{S^{\prime}}^{\min }=b_{S}^{\min }$. Since

$$
\frac{\partial X^{*}(S)}{\partial b_{S}^{\min }}=\frac{k}{(n-m+2)}>0
$$

and $n-m+2=n^{\prime}-m^{\prime}+2, X^{*}(S)$ decreases if $b_{i}<b_{S}^{\min }$ and remains constant if $b_{i} \geq b_{S}^{\min }$. Considering (16) and (17) in the text, it is evident that the coalitional payoff increases and the payoff of a non-member decrease if $b_{i}<b_{s}^{\min }$ and both remain constant if $b_{i} \geq b_{s}^{\min }$.

\section{Appendix III: Proposition 3}

Consider $n$ players and a given coalition $S$ with $m$ members. Suppose a singleton player $i$ joins coalition $S$ such that $S^{\prime}=S \cup\{i\}$ and hence $m^{\prime}=m+1$. Denote $b_{S^{\prime}}^{\min }$ the smallest $b_{k}$ in coalition $S^{\prime}$. Let $\Delta E^{*}=E^{*}(S)-E^{*}\left(S^{\prime}\right)$. Then using (14) in the text:

$$
\Delta E^{*}=\frac{r}{(n-m+2) q}\left[\left(1-b_{S}^{\min }\right)+\sum_{j \neq S}\left(1-b_{j}\right)\right]-\frac{r}{(n-m+1) q}\left[\left(1-b_{S^{\prime}}^{\min }\right)+\sum_{j \notin S^{\prime}}\left(1-b_{j}\right)\right] .
$$

After some basic manipulations, we derive:

$$
\operatorname{sign}\left(\Delta E^{*}\right)=\operatorname{sign}\left[-\left(1-b_{S}^{\min }\right)-\sum_{j \notin S}\left(1-b_{j}\right)-(n-m+2)\left(-1+b_{i}+b_{S}^{\min }-b_{S^{\prime}}^{\min }\right)\right] .
$$

If $b_{i}<b_{S}^{\min }$, then $b_{i}=b_{S^{\prime}}^{\min }$. Replacing $b_{S^{\prime}}^{\min }$ by $b_{i}$ in the expression above, we have:

$\operatorname{sign}\left(\Delta E^{*}\right)=\operatorname{sign}[A]$.

If $b_{i} \geq b_{S}^{\min }$, then $b_{S}^{\min }=b_{S^{\prime}}^{\min }$. Replacing $b_{S^{\prime}}^{\min }$ by $b_{S}^{\min }$ in the expression above, we have:

$\operatorname{sign}\left(\Delta E^{*}\right)=\operatorname{sign}[B]$. 
Since $A>0$ and $B>0$ by assumption in Appendix I, $\Delta E^{*}>0$.

Subtracting $\frac{1}{2} E_{S}$ on both sides of equality (A1) above, using the equilibrium values of variables and rearranging terms, we find:

$E_{S}^{*}(S)=\frac{r}{q}\left(1-b_{S}^{\min }\right)-E^{*}(S)$

From above we know that $E^{*}(S)>E^{*}\left(S^{\prime}\right), \quad b_{S}^{\min } \geq b_{S^{\prime}}^{\min }, \quad S^{\prime}=S \cup\{i\} \quad$ and hence $E_{S}^{*}(S)<E_{S^{\prime}}^{*}\left(S^{\prime}\right)$. Applying a similar procedure shows that $E_{j \notin S}^{*}(S)<E_{j \notin S^{\prime}}^{*}\left(S^{\prime}\right)$. Finally, since the stock decreases with the total fishing effort, as this is evident from equation (4) in the text, $X^{*}(S)<X^{*}\left(S^{\prime}\right)$. Taken together, this proves Proposition 3a, i.

Consider now the payoffs and let $\Delta \Pi_{S, S^{\prime}}^{*}=\Pi_{S}^{*}(S)-\Pi_{S^{\prime}}^{*}\left(S^{\prime}\right)$. Using (16) in the text, we find after some manipulation (proceeding along the same lines to sign $\Delta E^{*}$ ):

$\operatorname{sign}\left(\Delta \Pi_{S, S^{\prime}}^{*}\right)=\operatorname{sign}\left[1-(n-m+2)(n-m) b_{S^{\prime}}^{\min }+(n-m+1)^{2} b_{S}^{\min }+\sum_{j \notin S} b_{j}-(n-m+2) b_{i}\right]$.

If $b_{i}<b_{S}^{\min }$, then $b_{i}=b_{S^{\prime}}^{\min }$. Replacing $b_{S^{\prime}}^{\min }$ by $b_{i}$ in the expression above, we have:

$$
\operatorname{sign}\left(\Delta \Pi_{S, S^{\prime}}^{*}\right)=\operatorname{sign}\left[\left(1-(n-m+1) b_{i}+b_{S}^{\min }+\sum_{j \neq i \notin S} b_{j}\right)+\left((n-m+1)^{2}-1\right)\left(b_{S}^{\min }-b_{i}\right)\right] .
$$

The first term in brackets is condition $B>0$. The second term is strictly positive because $n>m$ (due to the assumption $S^{\prime}=S \cup\{i\}$ ) and the last term is positive by assuming $b_{i}<b_{S}^{\min }$.

If however $b_{i} \geq b_{S}^{\min }$, then $b_{S}^{\min }=b_{S^{\prime}}^{\min }$. Replacing $b_{S^{\prime}}^{\min }$ by $b_{S}^{\min }$ in the expression above, we have: 
$\operatorname{sign}\left(\Delta \Pi_{S, S^{\prime}}^{*}\right)=\operatorname{sign}\left[1-(n-m+1) b_{i}+b_{S}^{\min }+\sum_{j \neq i \notin S} b_{j}\right]$

where the term in brackets is condition $B>0$. Thus, $\Delta \Pi_{S, S^{\prime}}^{*}>0$.

A similar procedure along the lines of signing $\Delta \Pi_{S, S^{\prime}}^{*}$ (using conditions $A>0$ and $B>0$ ), letting $\Delta \Pi_{j \notin S, S^{\prime}}^{*}=\Pi_{j \notin S}^{*}(S)-\Pi_{j \notin S^{\prime}}^{*}\left(S^{\prime}\right)$ would show that $\Delta \Pi_{j \notin S, S^{\prime}}^{*}>0$. Taken together, this proves Proposition 3a, ii.

If superadditivity holds, then $\Pi_{S^{\prime}}^{*}\left(S^{\prime}\right) \geq\left(\Pi_{S}^{*}(S)+\Pi_{i}^{*}(S)\right), S^{\prime}=S \cup\{i\}, i \notin S$. Using (16) and (17) in the text, this implies:

$$
\begin{aligned}
& \frac{r p k}{(n-m+3)^{2}}\left(1-(n-m) b_{S^{\prime}}^{\min }+\sum_{j \notin S^{\prime}} b_{j}\right)^{2} \geq \\
& \frac{r p k}{(n-m+2)^{2}}\left(1-(n-m+1) b_{S}^{\min }+\sum_{j \notin S} b_{j}\right)^{2}+\frac{r p k}{(n-m+2)^{2}}\left(1-(n-m+1) b_{i}+b_{S}^{\min }+\sum_{k \neq i \notin S} b_{k}\right)^{2}
\end{aligned}
$$

Dividing through by rpk, assuming symmetric players, this requires:

$$
(1-b)^{2}\left[\left(\frac{n-m+2}{n-m+1}\right)^{2}-2\right] \geq 0
$$

or since $1-b>0$

$$
\frac{n-m+2}{n-m+1} \geq \sqrt{2} \Leftrightarrow n-m \leq \frac{2-\sqrt{2}}{\sqrt{2}-1} \square 1.41
$$

Hence if and only if $m=n-1$ does superadditivity hold. This proves Proposition $3 b$. Proposition $3 \mathrm{c}$ has been proved in the text. 
Table 1: Economic Fundamentals

\begin{tabular}{|c|c|c|c|c|c|c|c|}
\hline \multirow[t]{2}{*}{ Parameter } & \multirow[t]{2}{*}{$\begin{array}{l}\text { Stock } \\
X^{*}(S)\end{array}$} & \multicolumn{2}{|c|}{$\begin{array}{c}\text { Profit of S } \\
\qquad \Pi_{S}^{*}(S)\end{array}$} & \multicolumn{2}{|c|}{$\begin{array}{c}\text { Profit of } j \notin S \\
\qquad \Pi_{j}^{*}(S)\end{array}$} & \multicolumn{2}{|c|}{$\begin{array}{c}\text { Total Profits } \\
\Pi_{S}^{*}(S)+\sum_{j \notin S} \Pi_{j}^{*}(S)\end{array}$} \\
\hline & & gen. & sym. & gen. & sym. & gen. & sym. \\
\hline$c_{S}^{\min }$ & + & - & - & + & + & und. & - \\
\hline$c_{j}$ & + & + & + & $\begin{array}{c}k \neq j=+ \\
j=-\end{array}$ & $\begin{array}{c}k \neq j=+ \\
j=-\end{array}$ & und. & - \\
\hline all $c_{i}$ & + & - & - & - & - & - & - \\
\hline$p$ & - & und. & + & und. & + & und. & + \\
\hline$q$ & - & und. & + & und. & + & und. & + \\
\hline$k$ & + & und. & + & und. & + & und. & + \\
\hline$r$ & 0 & + & + & + & + & + & + \\
\hline
\end{tabular}

Legend: "gen." stands for general which allows for heterogeneous players, "sym." stands for symmetric players, $+(-)$ means an increase in this parameter (first column) has a positive (negative) effect on equilibrium levels in subsequent columns, and "und." stands for undetermined effect. In the case of a change of $c_{S}^{\min }$ and $c_{j}$, symmetry means symmetry before the change. "all $c_{i}$ " means a uniform change $d c_{i}=h>0$.

Table 2: Internal Stability Likelihood Estimates

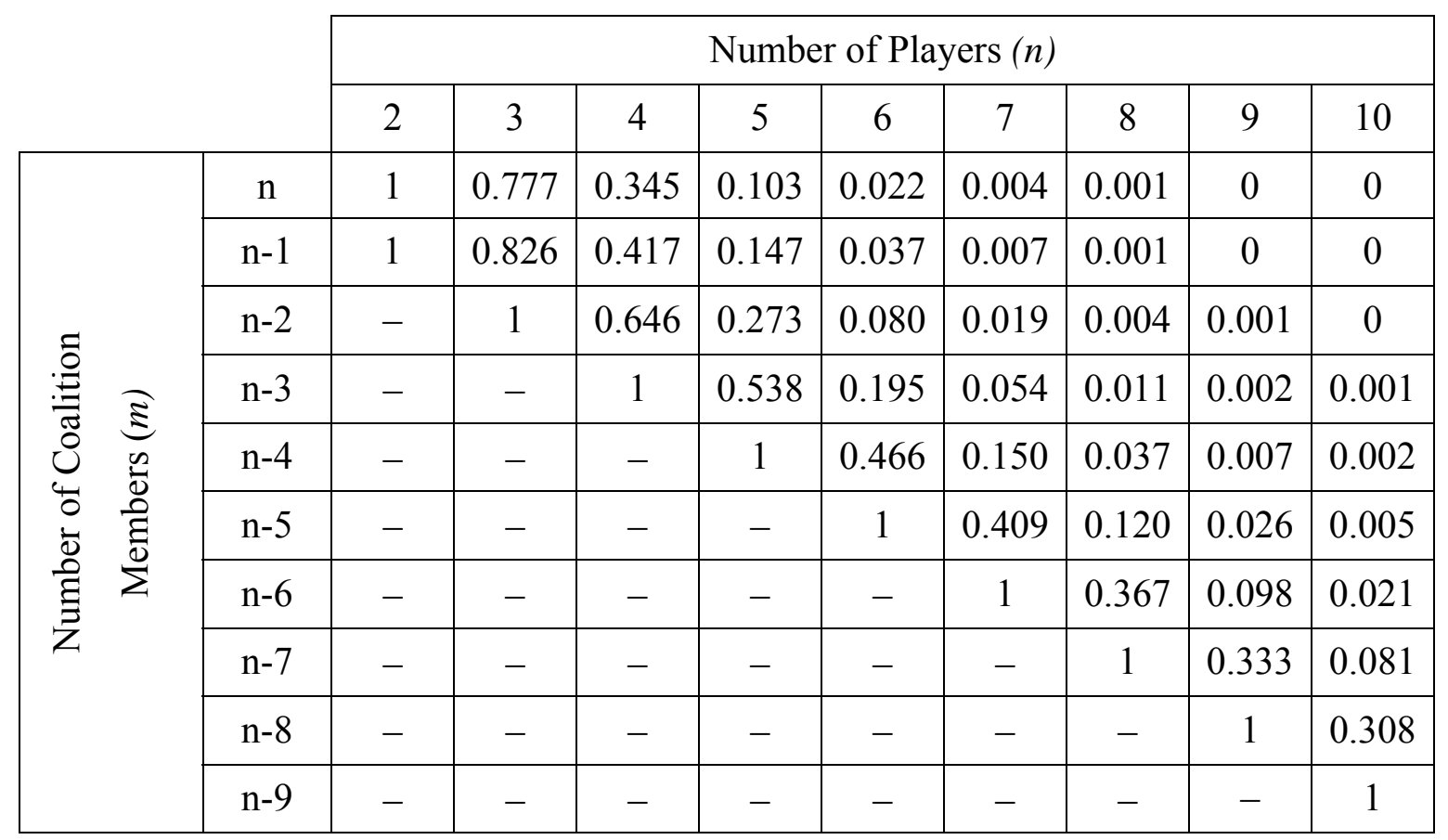


Table 3: External Stability Likelihood Estimates

\begin{tabular}{|c|c|c|c|c|c|c|c|c|c|c|c|}
\hline & \multicolumn{9}{|c|}{ Number of Players (n) } \\
\hline & & & 2 & 3 & 4 & 5 & 6 & 7 & 8 & 9 & 10 \\
\hline \multirow{10}{*}{ 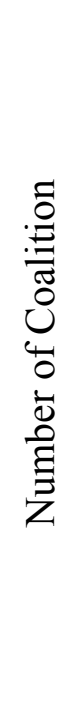 } & \multirow{10}{*}{$\begin{array}{l}\text { हే } \\
0 \\
\overline{0} \\
\text { है } \\
\sum^{0}\end{array}$} & $\mathrm{n}$ & 1 & 1 & 1 & 1 & 1 & 1 & 1 & 1 & 1 \\
\hline & & $\mathrm{n}-1$ & 0 & 0.223 & 0.655 & 0.897 & 0.978 & 0.996 & 0.999 & 1 & 1 \\
\hline & & $n-2$ & - & 0.028 & 0.412 & 0.773 & 0.938 & 0.988 & 0.998 & 1 & 1 \\
\hline & & $n-3$ & - & - & 0.036 & 0.499 & 0.832 & 0.959 & 0.992 & 0.999 & 1 \\
\hline & & $n-4$ & - & - & - & 0.035 & 0.560 & 0.867 & 0.969 & 0.995 & 0.999 \\
\hline & & $n-5$ & - & - & - & - & 0.030 & 0.610 & 0.891 & 0.977 & 0.996 \\
\hline & & $n-6$ & - & - & - & - & - & 0.026 & 0.648 & 0.908 & 0.982 \\
\hline & & $n-7$ & - & - & - & - & - & - & 0.025 & 0.677 & 0.922 \\
\hline & & $n-8$ & - & - & - & - & - & - & - & 0.020 & 0.702 \\
\hline & & $n-9$ & - & - & - & - & - & - & - & - & 0.017 \\
\hline
\end{tabular}

Table 4: Stability Likelihood and Success Indexes Estimates

\begin{tabular}{|c|c|c|c|c|c|c|c|c|c|c|}
\hline & \multicolumn{9}{|c|}{ Number of Players $(n)$} \\
\hline & & 2 & 3 & 4 & 5 & 6 & 7 & 8 & 9 & 10 \\
\hline \multirow{10}{*}{ 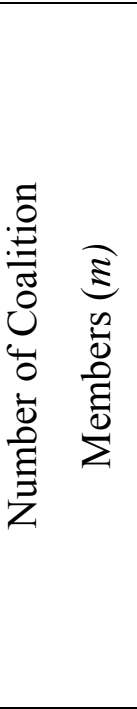 } & $\mathrm{n}$ & 1 & 0.777 & 0.345 & 0.103 & 0.022 & 0.004 & 0.001 & 0 & 0 \\
\hline & $\mathrm{n}-1$ & 0 & 0.127 & 0.149 & 0.074 & 0.023 & 0.004 & 0.001 & 0 & 0 \\
\hline & $\mathrm{n}-2$ & - & 0.028 & 0.148 & 0.101 & 0.036 & 0.010 & 0.002 & 0 & 0 \\
\hline & $\mathrm{n}-3$ & - & - & 0.036 & 0.126 & 0.071 & 0.023 & 0.005 & 0.001 & 0 \\
\hline & $\mathrm{n}-4$ & - & - & - & 0.035 & 0.112 & 0.053 & 0.015 & 0.003 & 0.001 \\
\hline & $n-5$ & - & - & - & - & 0.030 & 0.101 & 0.040 & 0.011 & 0.002 \\
\hline & $n-6$ & - & - & - & - & - & 0.026 & 0.090 & 0.031 & 0.007 \\
\hline & $\mathrm{n}-7$ & - & - & - & - & - & - & 0.025 & 0.082 & 0.025 \\
\hline & $\mathrm{n}-8$ & - & - & - & - & - & - & - & 0.020 & 0.076 \\
\hline & n-9 & - & - & - & - & - & - & - & - & 0.017 \\
\hline \multicolumn{2}{|c|}{$\overline{\mathrm{SGI}}(\mathrm{n})$} & 14.8 & 25.5 & 33.6 & 39.9 & 45.1 & 49.4 & 53.0 & 56.1 & 58.8 \\
\hline \multicolumn{2}{|c|}{$\overline{\mathrm{CGI}}(\mathrm{n})$} & 100 & 87.2 & 55.4 & 30.4 & 16.3 & 9.3 & 5.9 & 4.0 & 2.8 \\
\hline
\end{tabular}


Table 5: Success Indexes Estimates: Asymmetry and Efficiency Effect

\begin{tabular}{|c|c|c|c|c|c|c|c|c|c|c|}
\hline \multirow{2}{*}{$\begin{array}{l}\text { Range } \\
\text { of } b_{i}^{\prime} \mathrm{s}\end{array}$} & & \multicolumn{9}{|c|}{ Number of Players } \\
\hline & & 2 & 3 & 4 & 5 & 6 & 7 & 8 & 9 & 10 \\
\hline & & \multicolumn{9}{|c|}{ Asymmetry Effect } \\
\hline \multirow{2}{*}{0.2} & $\overline{\mathrm{SGI}}(\mathrm{n})$ & 11.1 & 25.0 & 36.0 & 44.4 & 51.0 & 56.3 & 60.5 & 64.0 & 66.9 \\
\hline & $\overline{\mathrm{CGI}}(\mathrm{n})$ & 100 & 0.0 & 0.0 & 0.0 & 0.0 & 0.0 & 0.0 & 0.0 & 0.0 \\
\hline \multirow{2}{*}[0.1;0.3]{} & $\overline{\mathrm{SGI}}(\mathrm{n})$ & 16.1 & 29.9 & 39.2 & 45.6 & 50.1 & 53.5 & 56.2 & 58.7 & 60.8 \\
\hline & $\overline{\mathrm{CGI}}(\mathrm{n})$ & 100.0 & 43.8 & 17.3 & 9.9 & 6.6 & 4.7 & 3.5 & 2.7 & 2.1 \\
\hline \multirow{2}{*}[0;0.4]{} & $\overline{\mathrm{SGI}}(\mathrm{n})$ & 17.3 & 28.2 & 35.5 & 41.2 & 45.9 & 49.9 & 53.3 & 56.3 & 59.0 \\
\hline & $\overline{\mathrm{CGI}}(\mathrm{n})$ & 100.0 & 76.7 & 42.7 & 23.3 & 13.5 & 8.4 & 5.5 & 3.9 & 2.8 \\
\hline & & \multicolumn{9}{|c|}{ Efficiency Effect } \\
\hline \multirow{2}{*}[0;0.2]{} & $\overline{\mathrm{SGI}}(\mathrm{n})$ & 15.8 & 29.7 & 39.4 & 46.2 & 50.9 & 54.4 & 57.2 & 59.5 & 61.6 \\
\hline & $\overline{\mathrm{CGI}}(\mathrm{n})$ & 100 & 38.9 & 15.2 & 8.5 & 5.7 & 4.1 & 3.1 & 2.4 & 1.9 \\
\hline \multirow{2}{*}[0.2;0.4]{} & $\overline{\mathrm{SGI}}(\mathrm{n})$ & 16.4 & 29.9 & 38.8 & 44.8 & 49.0 & 52.4 & 55.3 & 57.9 & 60.2 \\
\hline & $\overline{\mathrm{CGI}}(\mathrm{n})$ & 100.0 & 50.2 & 19.8 & 11.4 & 7.6 & 5.4 & 4.0 & 3.0 & 2.3 \\
\hline \multirow{2}{*}[0.4;0.6]{} & $\overline{\mathrm{SGI}}(\mathrm{n})$ & 17.2 & 29.3 & 36.9 & 42.3 & 46.8 & 50.6 & 53.8 & 56.7 & 59.2 \\
\hline & $\overline{\mathrm{CGI}}(\mathrm{n})$ & 100 & 67.8 & 31.6 & 17.6 & 11.1 & 7.3 & 5.0 & 3.6 & 2.6 \\
\hline
\end{tabular}

